\title{
Assessing the Openness of Anthropology Journals
}

Melody Dale, Nickoal Eichmann-Kalwara, Sheeji Kathuria, and Mary Ann Jones

This is the accepted version (June 30,2017 ) but not the published version to appear in the

October 2017 special issue of the Journal of Scholarly Publishing 49, no. 1.

This study analyses the extent of gold open access (OA) publishing options in 377 anthropology journals by applying a six-level coding scheme $(0=$ nontransparent publishing, 5 = fully $O A$, i.e., free to read and publish without embargo). This analysis is meant to simplify the process of identifying OA journal publishing options in the discipline of anthropology, in addition to sharing findings on some of the prominent issues in OA publishing as they relate to anthropology journals, including non-transparency among publishers and the prevalence and price of article processing charges (APCs). We conclude that publishers should be more transparent about their OA publishing options and policies by providing conspicuous and straightforward information to potential authors. Further, we find that in the anthropology scholarly communication ecosystem, APCs for hybrid journals are more expensive than those for fully gold OA journals, thus contradicting the assumption that gold $\mathrm{OA}$ is more costly to researchers.

Keywords: open access, anthropology, scholarly communication, article processing charges

\section{Introduction and Background}

In 2008 the American Anthropological Association (AAA) began moving its publishing operation from the University of California Press to commercial publisher Wiley-Blackwell, which caused an increase in subscription prices for some of the AAA's journals. Then, in 2012, Tom Boellstorff, who was then editor-in-chief of American Anthropologist, encouraged current and future members of the AAA to start laying the groundwork for open access (OA) publication practices in the association. ${ }^{1}$ This initiative was largely due to association members' growing interest in alternative publishing models and a shared concern that partnering with Wiley-Blackwell was a 'Faustian bargain that undercut the universities that made our scholarship 
possible in the first place. ${ }^{2}$ Furthermore, in sympathy with the growing open scholarship movement, some anthropologists have also advocated OA models for greater visibility and dissemination of anthropological research. Fortunately, some scholarly societies have had successful results with increased membership and revenue through partnerships supporting $O A$, such as the Society of Cultural Anthropology through its journal Cultural Anthropology. ${ }^{3}$ This success owes partly to the fact that 'scholars liked the idea of being a part of an innovative and fair publishing model, and were willing to pay section dues even for a journal they could receive for nothing. ${ }^{4}$ However, as Brad Weiss notes, 'open access does not mean that publication is free, ${ }^{5}$ and not everyone in the AAA has welcomed or accepted $O A$ as a viable publishing model. Michael Chibnik, editor-in-chief of American Anthropologist after Boellstorff, argued that such a model would require large grants or otherwise would compound the problem of unpaid editorial labour, ${ }^{6}$ which remains a problem for a variety of journals. Despite this, positive sentiments about $O A$ remain strong among anthropologists who call for continued exploration in, and experimentation with, OA publishing models that are sustainable and scalable.

Seeing this trend, we sought to explore the extent of openness in anthropology journals. We wanted to examine the extent to which OA publishing is an option for scholars in anthropology; more specifically, we wanted to investigate how publishers portray their publishing options to authors. While a longitudinal analysis might help to determine whether the prominence of OA options affects a journal's reputation (as seen with Cultural Anthropology), we thought it worthwhile to evaluate how publishers themselves communicate publishing options to authors and to see whether there are any correlations between having OA options available, requiring article processing charges (APCS), and making those OA options transparent to authors. For this exploratory study, we compiled a large sample of anthropology journals by creating a master list of titles sourced from the AAA, the World Council of Anthropological Associations (WCAA), Journal Citation Reports (JCR), Scimago Scientific Journal Rankings (SJR), and the Directory of Open Access Journals (DOAJ). We rated the journals on a scale of openness: 0 = non-transparent publishing options, $1=$ subscription only, 2 = OA option, 3 = completely OA with an APC, 4 = delayed OA (free to read and publish after an embargo), and 5 = fully OA (free to read and publish without an embargo). 
While prospective authors can refer to the DOAJ if they are interested in publishing in OA journals and want to search by APCs, copyright licenses, or country of origin, we undertook our study with the assumption that not all authors are familiar with the DOAJ. Moreover, we wanted to survey the scholarly journal landscape of anthropology at large, across the spectrum of subscription-only journals to fully gold OA.

This project was inspired by the work of Micah Vandegrift and Chealsye Bowley, who analyzed library and information science journals and created a Journal Openness Index. Vandegrift and Bowley assessed copyrights, reuse rights, and author posting rights by assigning numerical values to SPARC'S Open Access Spectrum $^{8}$ and ranked library science journals accordingly. Adopting a similar methodology to study anthropology journals seemed relevant to us given the increased awareness and advocacy of OA publishing models in the discipline of anthropology. Furthermore, Elsevier's May 2016 purchase of the Social Science Research Network, or SSRN, which served as a major OA repository for anthropology, incited skepticism within the social sciences and raised concerns about the future of this OA venue. ${ }^{9}$ As such, we wanted to take a snapshot of the state of publishing in anthropology to see how its scholarly communication ecosystem stands in relation to $\mathrm{OA}$.

When choosing a forum in which to publish their scholarship, authors tend to make choices based on relevancy, impact factor, prestige, acceptance rates, and effects on promotion and tenure applications. ${ }^{10}$ However, as scholarly publishing continues to evolve, these criteria have expanded to include additional publishing concerns, such as distribution, archiving, and reuse rights. ${ }^{11}$ While assessments of disciplinary approaches to open scholarship have focused primarily on scholars' attitudes toward OA publishing and practices, ${ }^{12}$ we sought instead to shed light on the level of transparency that publishers provide for the OA publishing options they make available to authors.

\section{Current Models of Journal Publishing}

Academic publishing currently has three primary journal publishing models. Most popular and best understood by authors and readers is the subscription journal. This model is the traditional toll-access model, whereby a reader must have institutional access to a journal, buy a subscription, or pay per article to read content. Subscription journals account 
for a big part of many university and research libraries' collections budgets due to the substantial cost of providing research journals to faculty and students. Despite rising subscription costs and decreasing library budgets, the subscription model continues to be the mainstay method by which university libraries provide access to periodicals. ${ }^{13}$

The second type of journal publishing model is fully OA journals, which may or may not require an APC. Fully OA serials have become a hot topic in the wake of ever-increasing subscription prices. ${ }^{14}$ Levels of openness exist on a spectrum, including green $\mathrm{OA}$, which allows authors to archive specific versions of papers as permitted by copyright contracts; gold OA, where APCs are generally the only requirement for $O A$ publication; and diamond $O A$, where articles are free to publish and free to read. ${ }^{15}$ The options available vary by journal and publisher. The OA movement received a boost when the National Institutes of Health $(\mathrm{NIH})$ instated a mandate for federally funded peer-reviewed research to be more readily available to the people (i.e., the taxpayers) whose taxes finance federal grants that subsidize published research. ${ }^{16}$ The NIH mandate, which began in 2008, became the impetus for additional federal agencies to follow suit, resulting in more federally funded re-search outcomes being accessible to the general public. This mandate, in turn, resulted in larger conversations in academia about how to better disseminate research results to those who need it but who are not affiliated with a university where access is provided by a library. OA offers opportunities for researchers to make a greater impact with their research by reaching a multitude of readers never before considered worthy stakeholders in academic research.

The third publishing model is a combination of subscription and $O A$, generally known as hybrid journals. These are subscription journals with select articles made openly available to readers when authors pay an APC. The hybrid model allows authors to satisfy the OA mandates of federal agencies while still publishing in their discipline's top journals. For example, Nature is a prestigious generalist science journal, but without the hybrid option, authors could not publish in Nature and have their research immediately open for public access. Seeing the need for individual articles in subscription journals to be open to the general public, publishers created a fee-based system providing authors with a means to comply with the mandate while still publishing in desirable top-rated journals. 
JCR and SJR primarily consist of journals written in English, and 'large parts of the world are excluded from the highest ranked academic journals because they are not able to write in English to a sufficiently high standard. ${ }^{25}$ In order to be sensitive to issues of language hegemony in anthropology journals, we included titles from the WCAA. ${ }^{26}$ How-ever, since we searched publishers' websites to determine the availability of OA choices, we relied on browser translation tools, which did not always function properly, thereby forcing us to omit some non-English publications.

We also excluded any journal titles that exhibited potentially unethical or 'predatory' practices. To make these determinations, we first investigated positive indicators, which included verifying whether a questionable title was indexed in JCR, SJR, or the DOAJ. We also checked for publisher or society listings with the Open Access Scholarly Publishing Association (OASPA), and we reviewed journal editorial boards (if listed). We also took into consideration Jeffrey Beall's Scholarly Open Access blog, known colloquially as Beall's list, which was taken down in January $2017 .{ }^{27}$ However, we did not view this as the definitive blacklist of predatory journals, so we included two titles featured on his list after finding positive indicators of quality, such as consistent publication history, impact factors, indexing in the DOAJ, and reliable information about editorial board members. $^{28}$

We excluded a total of forty-eight titles, most of which had ceased publication at the time of our data gathering. Furthermore, we removed titles that were not peer reviewed. One journal's website remained under maintenance for the duration of our project, so we excluded it from our assessment.

Overall our data set reflects the discoverability of OA options from fall 2015 to spring 2016, so changes to journal webpages since then are not reflected in our data. For instance, since the start of our coding in fall 2015, OA publishing options for Sage publications have increased in visibility on publisher and journal websites, which may make our coding inconsistent with later revised content.

Finally, while we gathered information on each journal's impact in SJR and JCR as part of our title gathering process, we decided not to investigate how APCs correlate with impact factors. While 31 per cent of our coded titles were featured in JCR and nearly 75 per cent were listed in SJR, these measures do not always serve as the best indicators of quality. For instance, OA journals may lack established reputations and may not have clear impact indicators, while some journals rely on other impact indicators reflective of their country of publication. ${ }^{29}$ 
In all, we assessed 377 anthropology journals. We have made these

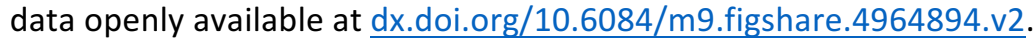

Journal Coding

As librarians who consult with researchers on scholarly communication issues, we possess knowledge of the academic publishing lexicon and ecosystem, but in order to code journal titles consistently, we needed to set aside that existing knowledge and rely on a common coding scheme to ensure objectivity. In other words, even if one of us was aware of an OA option for a subscription journal, that person, as a coder, had to apply our scheme without foreknowledge and search for visual and textual indicators of any OA options on the pertinent website(s). The website areas where one might find OA information and publishing options varied by publisher and journal. Some sites required visitors to navigate to submission guidelines that, potentially, mentioned publishing options.

Openness in publishing spans from reuse rights to author rights; however, for the purposes of this research, we focused on the OA publishing options available to authors. We used a grounded theory approach in which we individually assigned categories and themes to our data with degree of openness serving as our lens; we then compared our individual findings and built consensus around those themes to develop a coding scheme. To do this, we divided among ourselves separate subsets of titles that comprised 25 per cent of our master list, and we each coded a subset. After this initial round of coding, a second subset of titles was assigned to each coder as a method of intra-group peer review and confirmation of evaluations for subsequent coding. The six codes we assigned resulted in a scale from least-open to most-open publishing options (Table 1).

When journal websites failed to include any information on publishing options, we considered this 'non-transparent' and coded those titles as 0 . If a journal indicated that it was a subscription journal open only to subscribers and did not provide authors the option to pay or apply for $\mathrm{OA}$, we assigned it a 1 . Since commercial publishers have increasingly moved toward a model that keeps articles closed to non- 
Table 1. Coding scheme for level of openness

\begin{tabular}{lll} 
Code & Description & Definition \\
\hline 0 & Non-transparent & $\begin{array}{l}\text { Information on publishing options not readily } \\
\text { available; assumed to be closed/subscription } \\
\text { journal } \\
\text { with no OA option }\end{array}$ \\
1 & Closed & $\begin{array}{l}\text { Subscription journal, no obvious OA option } \\
\text { Subscription journal, hybrid (not fully OA); authors } \\
\text { pay APC for OA option }\end{array}$ \\
3 & Open option & $\begin{array}{l}\text { Entire journal is free to read, but authors pay APC } \\
\text { with no embargo } \\
\text { Entire journal is free to read, with no APC, but } \\
\text { articles have embargo period before becoming OA } \\
\text { Free to read, free to publish OA (no APC or } \\
\text { embargo) }\end{array}$ \\
5 & Open with embargo &
\end{tabular}

subscribers unless authors pay an APC to make their work OA, we assigned a 2 to this hybrid model, indicating an 'open option.' We found some journals that were fully OA to readers, but they required all authors whose articles were accepted after peer review to pay an APC. These we coded 3, 'open with APC.' Toward more open options, we encountered journals that published all content on the open Web, with the only barrier being time. In other words, these journals were $O A$, but the individual articles were closed to readers for an embargo period. We assigned these a code of 4 . Finally, journal titles that published articles immediately without embargo and did not charge their contributors an APC were assigned a 5 as 'open.'

\section{Findings}

In this section, we report the distribution of journals based on our assigned codes. We also report how APCs differed by the type of journal, with a drastic difference being found for the average APC of hybrid versus open journals.

\section{Coding Distribution}

Overall, the state of OA publishing in anthropology remains limited; around 64 per cent of the journals (coded 0-2) in our data set were non-transparent about publishing options, were subscription based, or 


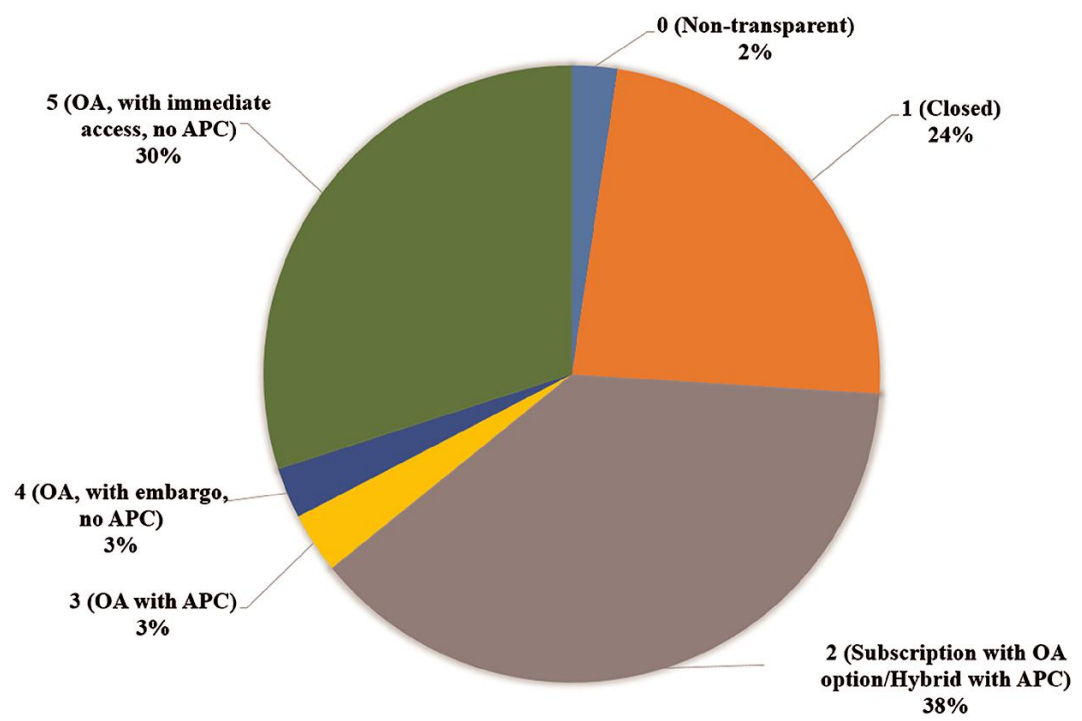

Figure 1. Openness of anthropology journals coded according to six-level scheme

followed a hybrid model (Figure 1). Some journals' websites failed to communicate any OA publishing options, suggesting that no option existed except for subscription-based toll access. It is possible that some journals may in fact give authors a choice to publish their final article openly but do not make these options apparent on their website.

The largest subset, representing around 38 per cent of journals, was coded 2. This implies that the preferred publishing model of anthropology journals is a hybrid system, where the option of publishing in OA requires that authors pay an APC to a subscription-based journal. In addition, around 24 per cent of journals were coded 1 , which are subscription-based journals that provide no options for OA publishing. Some large publishers offered OA options; however, the OA language was not clearly displayed on the journal's website. The code of 0 was necessary when the publisher's webpage was unclear or nontransparent about available options. As only around 2 per cent of the data set was coded 0 , it is clear that the large majority of journals provided some clear designation of OA publishing options.

While the majority of journals were coded subscription-only or hybrid, we found that the other 36 per cent were OA. This included anthropology journal titles that were fully OA (code 5), required an 


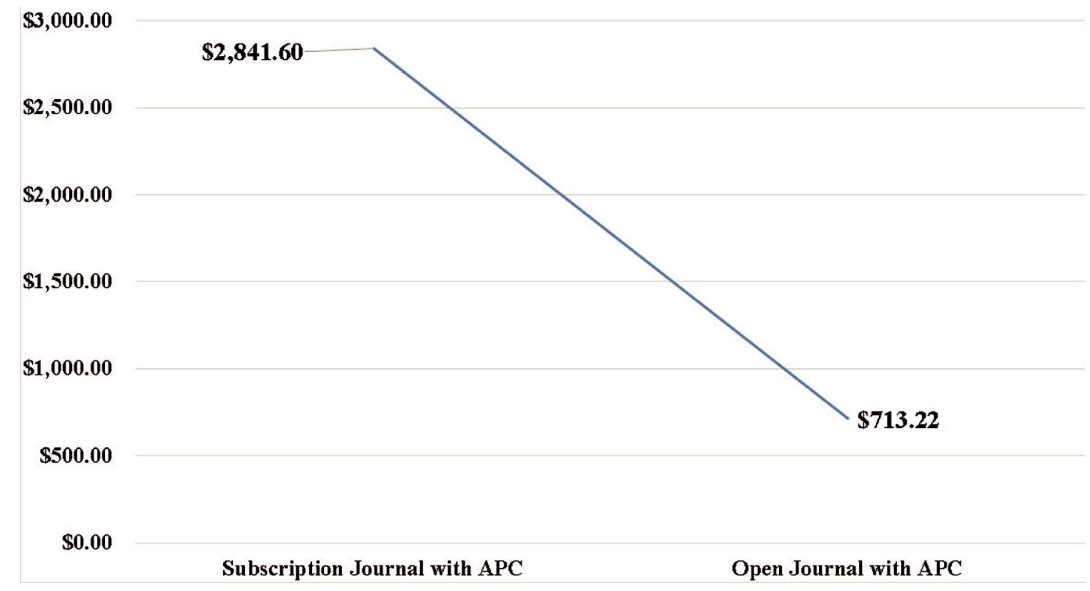

Figure 2. Average APC by type of journal

embargo period before becoming OA (code 4), or were fully OA but required an APC (code 3 ). The second-largest group consisted of journals coded 5 , on the other end of the spectrum from closed subscription journals. These journals were completely open without APCs or embargoes and amounted to about 30 per cent of our data set. Journals coded 3 or 4 were about equal in proportion, with each representing about 3 per cent of the distribution. The codes 3 and 4 consisted of journals that were completely free to access and read but that imposed a slight burden on the author - either an APC or an embargo period prior to OA. There-fore, while subscription-only publishing models remained dominant, OA was not far behind.

\section{APC Comparison}

All of the APCs were normalized and converted to a US dollars ex-change rate. Our analysis indicates that hybrid journals (code 2) had an average APC of $\$ 2841$, whereas APC-requiring OA journals had an average APC of $\$ 713$ (code 3). The average APC for hybrid journals was four times higher than that of APC-requiring OA journals (Figure 2). One would presume that OA journals rely on APCs to fund their publishing operations and might therefore charge more, whereas subscription-based journals that receive revenue from subscriptions would not need such high APCs. 


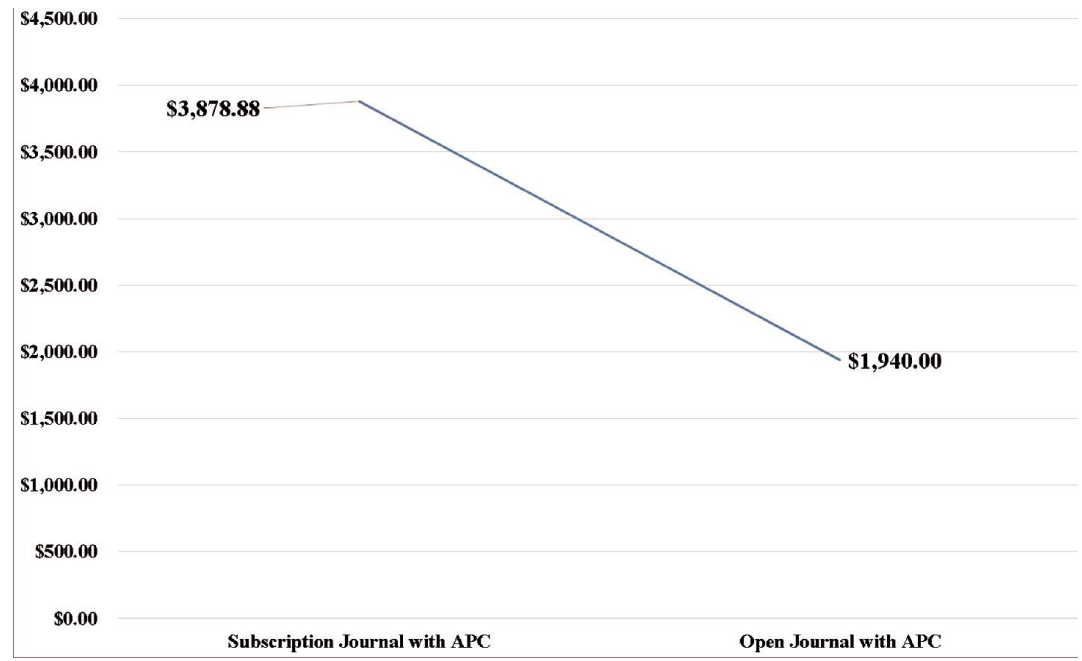

figure 3. Highest APC by type of journal

The highest recorded APC for a subscription-based journal in our sample was \$3879, whereas the highest APC for an OA journal was $\$ 1940$ (Figure 3). We found that subscription-based journals were, on average, charging much higher APCs compared to OA journals, which were charging lower APCs in their author-pay model. Finally, five journals clearly required an APC, but they asked authors to contact the publisher to learn the exact cost. In other words, transparency regarding APCs varied as well.

In order not to skew the data, we eliminated one OA journal's APC from the average, the Journal of the Anthropological Society of Oxford. At the time of our data gathering, this journal required an APC of $\$ 0.02$ to comply with the policy of the Higher Education Funding Council for England. In the website's own words, '[APCs] should be paid in cash when the author bumps into one of the Editors or anyone who knows them. Why? Because on one interpretation of the guidelines only journals charging APCs are eligible. ${ }^{30}$ This policy has since changed. ${ }^{31}$

\section{Conclusions}

We conclude that a shift is required from publishers to make OA options more transparent to authors, who are increasingly required to make their research publicly available in compliance with an open scholarship ethos, 
and publishers need to be flexible toward these needs. Through our analysis, we see that the scholarly communication ecosystem for anthropology leans toward closed and hybrid models, showing that continued efforts to support OA models are required. In the field of anthropology, an open ethos continues to grow, making $O A$, author rights, and reuse important motivators for assessing journals. Despite this growing attraction to OA options, anthropology scholars have limited options for OA publication. Publishers of anthropology journals prefer the subscription and author-pay hybrid models, as our data indicate.

Anthropology research tends to be funded by a wide variety of funders, including both public and private sources, with many requiring OA publishing. This includes federal funders such as the NIH and the National Science Foundation (NSF) and private funders such as the Gates Foun-dation. ${ }^{32}$ In a 2011 hearing before the Subcommittee on Research and Science Education (of the House Committee on Science, Space, and Technology), the NSF's Social, Behavioral, and Economic Sciences (SBE) section reported that the SBE supports approximately 58 per cent of federally funded basic research in academic institutions in the social, behavioral, and economic science fields. ${ }^{33}$ While this NSF section includes many social science specialties, the statement suggests that some anthropology research does have financial support that comes with an OA mandate for federally supported research outcomes.

Complicating the matter of taxpayer-funded research is the problematic nature of subscription journals with an OA option that requires payment of an APC. With APCs, federally funded research often results in multi-ple payments to the publisher. ${ }^{34}$ In some disciplines, and depending on the federal agency, portions of taxpayer-funded grants can be used to pay APCs. ${ }^{35}$ However, this money could be used more effectively in the research process instead of subsidizing a double-dipping effect. That is, in many cases publishers receive payment to make an article $O A$ and receive a second payment in the form of a subscription to the journal, oftentimes from taxpayer-funded libraries. ${ }^{36}$ Why should taxpayers be responsible to publishers for payment on both ends of the research process? This is a central question in the $O A$ debate and undoubtedly will continue as long as publishers charge authors to publish research outcomes.

We conclude that publishers should be more transparent regarding publishing choices and policies by providing straightforward information on OA options to potential authors. Further, we find that in the 
anthropological scholarly communication ecosystem, hybrid journal APCs are more expensive than those for fully OA journals, thus contradicting the assumption that gold $\mathrm{OA}$ is more costly to researchers.

Researchers find themselves in a quandary when faced with a need to publish in prestigious publishing outlets and with a moral obligation to support free and open information. ${ }^{37}$ The AAA, and especially the Society for Cultural Anthropology within it, acknowledges that this is often overshadowed by misunderstandings of OA within the discipline. However, the AAA is seeking a balance between financing OA journals with grants that would otherwise fund individual APCs, and funding publishing operations with society membership fees. Cost shifting from the subscriber to the author is not a sufficient model to promote open-ness of research and data. A non-profit scholarly society's OA journals with APCs are a slightly different take on the past model of page fees. In some ways, even with OA from APCs, publishers may be using taxpayer-funded research by claiming that 'free to read' is worth the extra expense of the funding agency. The 'closed' option, when dissected, might suggest that many society publishers are choosing this option to retain their source of revenue through journal subscriptions. Finally, it seems that policies and procedures remain outdated and have not kept pace with an evolving research ethos that promotes open scholarship practices. As Boellstorff notes, 'There is a fundamental contradiction between the often-repeated goal of making anthropology more public and relevant on the one hand and the lack of OA on the other hand. ${ }^{38}$

\section{Future Research}

Although this research surveyed the OA options available to authors in anthropology, the most straightforward expansion of this study would be to include other disciplines. We hope this article will give subject-area specialist librarians a model by which to conduct a similar assessment for their chosen discipline. While we focused on general openness, as well as APCs and embargoes, future studies could expand to include publishers' communication of copyright options, reuse rights, and archiving rights, as Vandegrift and Bowley did in their study of library science journals.

Another direction for future research could compare the four fields of anthropology - biological anthropology, cultural anthropology, linguistic anthropology, and archaeology - or examine each field on its own. 
Further research into the specialties within the discipline will provide a more granular review of the willingness of scholars and journals to support OA publication. It would be worth investigating how anthropologists have secured funding for OA publications and if indeed they have sufficient funds to pay APCs, be they funded by federal grants or by OA subventions from their institutions. Another point to consider is that OA policies and funding models to meet mandates differ among countries; such variations may influence local disciplinary scholarly communication ecosystems. As such, geographical and economic comparisons of OA journals may be a worthy direction for exploration.

Finally, at the time of writing, our data reflect what we could gather in late 2015 and early 2016; since then, our sources of journal lists may have been updated. Furthermore, publisher websites continue to evolve, whether in content or structure; as such, additional research could be conducted to compare our findings with updated data.

\section{Acknowledgements}

Many thanks to Juliann Couture, Social Sciences Librarian at the University of Colorado Boulder, for her insightful feedback, and to Andrew Johnson, Data Management Librarian at the University of Colorado Boulder, for his time and expertise in guiding us on best practices for data reproducibility. 


\section{Notes}

1. T. Boellstorf, 'Why the AAA Needs Gold Open Access,' American Anthropologist 114 (2012): 389-93.

2. B. Weiss, 'Open Access and the Transformation of Academic Publishing: A View from Cultural Anthropology,' Parameters, September 20, 2016, http://parameters. ssrc.org/2016/09/open-access-and-the-transformation-ofacademic-publishing-a-view-from-cultural-anthropology/.

3. A. Jiménez, A. Corsín, D. Boyer, J. Hartigan, and M. de la Cadena, 'Open Access: A Collective Ecology for AAA Publishing in the Digital Age,' Cultural Anthropology, May 27, 2015, https://culanth.org/fieldsights/684-open-access-acollective-ecology-for-aaa-publishing-in-the-digital-age.

4. Ibid.

5. Ibid.

6. M. Chibnik, 'Open Access,' American Anthropologist 117 (2015): 22528, doi:10.1111/aman.12231.

7. M. Vandegrift and C. Bowley, 'Librarian, Heal Thyself: A Scholarly Communication Analysis of LIS Journals,' In the Library with the Lead Pipe (April 23, 2014), http://www.inthelibrarywiththeleadpipe.org/2014/healthyself/.

8. SPARC, PLOS, and OASPA, 'HowOpenIsIt: Open Access Spectrum,' 2014, https://www.plos.org/how-open-is-it. SPARC stands for the Scholarly Publishing and Academic Resources Coalition.

9. T. Leeper, 'Elsevier Purchase SSRN: Social Scientists Face Questions over Whether Centralised Repository Is in Their Interests,' LSE Impact of Social Sciences (blog), May 18, 2016, http://blogs.Ise.ac.uk/impactofsocialsciences/2016/ 05/18/elsevierpurchase-ssrn-social-scientists-face-questions-over-whether-centralised-repositoryis-in-their-interests/.

10. S. Chrisomalis, 'Talking about Impact: A Handbook for Pre-Tenure Humanists and Social Scientists,' Anthropology Faculty Research Publications, January 1, 2016, http://digitalcommons.wayne.edu/anthrofrp/2.

11. C. Kelty, M. Fischer, A. Golub, J. Jackson, K. Christen, M. Brown, and T. Boellstorff, 'Anthropology of/in Circulation: The Future of Open Access and Scholarly Societies,' Cultural Anthropology 3 (2008): 559-88.

12. See, for instance, Nature Publishing Group, 'Author Insights 2015 Survey,' September 23, 2015, doi:10.6084/m9.figshare.1425362.v7; R. Serrano-Vicente, R. Melero, and E. Abadal, 'Open Access Awareness and Perceptions in an Institutional Landscape,' Journal of Academic Librarianship 42, no. 5 (2016): 595-603.

13. A. Allison, D. Boyer, and C. Piot, 'Financing Open Access: Introducing Friends of Cultural Anthropology,' Cultural Anthropology 31 (2016): 159-61, https://culanth. org/articles/804-financing-open-access-introducing-friends-of.

14. S. Dyas-Correia, 'SCOAP3 and Open Access,' Serials Review 35 (2009): 264-71.

15. See Open Access Academy, 'Types of Open Access,' 2016, http://web.archive.org/web/20160911055742/http://www.oaacademy.org/typ es-of-open-access.html; 
P. Suber, 'Open Access Overview,' last modified December 5, 2015, http://legacy.earlham.edu/ peters/fos/overview.htm.

16. National Institutes of Health, 'NIH Public Access Policy Details,' last modified March 25, 2016, https://publicaccess.nih.gov/policy.htm.

17. Springer Science+Business Media, ' Open Choice: Springer Adds New Publication Model,' July 1, 2004, http://www.springer.com/about+springer/media/pressreleases\%3FSGWID=0-11002-2-803577-0.

18. R. Van Noorden, 'The True Cost of Science Publishing,' Nature 495 (March 2013): 426-9, http://psgsc.wisc.edu/wp-content/uploads/sites/89/2012/09/vanNoorden-2016-.pdf.

19. R. Poynder, 'Open Access: What Price Affordability?,' Ecancermedicalscience (December 2014): 1-3.

20. J. Jackson and R. Anderson, 'Anthropology and Open Access,' Cultural Anthropology 29, no. 2 (2014): 236-63.

21. D. Solomon and B. Björk, 'A Study of Open Access Journals Using Article Processing Charges,' Journal of the American Society for Information Science \& Technology 63, no. 8 (August 2012): 1485-95.

22. W. Crawford, 'Starting Dates and the Gold Rush,' Library Technology Reports 51, no. 6 (August 2015): 18-21.

23. D. Solomon and B. Björk, 'Publication Fees in Open Access Publishing: Sources of Funding and Factors Influencing Choice of Journal,' Journal of the American Society for Information Science \& Technology 63, no. 1 (2012): 98-107.

24. D. Kingsley, 'Paying for Publication: Issues and Challenges for Research Support Services,' Australian Academic \& Research Libraries 45, no. 1 (2014): 262-81.

25. D. Zeitlyn and S. Lyon, 'Varieties of Openness and Types of Digital Anthropology,' Durham Anthropology Journal 18, no. 2 (2012): 97-111.

26. D. Miller, 'Open Access, Scholarship and Digital Anthropology,' HAU: Journal of Ethnographic Theory 2 (2012): 385-411.

27. J. Beall, ‘Beall's List: Potential, Possible, or Probable Predatory Scholarly OpenAccess Publishers,' last modified December 31, 2016, http://web.archive.org/web/20170112125427/https://scholarlyoa.com/publishers . Beall voluntarily shut down his blog in early 2017. His discontinued list now only exists on mirror sites online and has been recreated as Cabell's New Predatory Journal Blacklist.

28. For more on journal quality assessment, see M. Berger and J. Cirasella, 'Beyond Beall's List: Better Understanding Predatory Publishers,' College \& Research Libraries News 76, no. 3 (2015): 132-5.

29. For more on comparing impact factors between $O A$ and subscription journals, see B. Björk and D. Solomon, 'Open Access versus Subscription Journals: A Comparison of Scientific Impact,' BMC Medicine 10 (2012): 73, doi:10.1186/1741-7015-10-73. 
30. See the archived copyright and APCs statement for the Journal of the Anthropological Society of Oxford at https://web.archive.org/web/20151018061652/http://www.anthro.ox.ac.uk/p ublications/jaso/copyright-and-apcs/.

31. See http://www.hefce.ac.uk/pubs/year/2016/201635/ for new policy details.

32. Consortium of Social Science Associations, 'Social \& Behavioral Science: Federal R\&D Funding by State,' 2017, http://www.cossa.org/wpcontent/uploads/2016/12/ 50-States-DC-Fact-Sheets.pdf; Bill and Melinda Gates Foundation, 'Open Access Policy,' accessed August 26, 2017, https://www.gatesfoundation.org/How-We-Work/General-Information/OpenAccess-Policy.

33. U.S. Congress, House Subcommittee on Research and Science Education of the Committee on Science, Space, and Technology, Social, Behavioral, and Economic Science Research: Oversight of the Need for Federal Investments and Priorities for Funding, 112th Cong. 1st sess. (2011), https://www.gpo.gov/fdsys/pkg/CHRG-112hhrg66563/pdf/CHRG112hhrg66563.pdf.

34. Committee for Economic Development, 'The Future of Taxpayer-Funded Research: Who Will Control Access to the Results,' 2012, http://www.emaxwell.net/linked/ DCCReport_Final_Feb2012.pdf.

35. National Institutes of Health, 'NIH Grants Policy Statement: 7.9 Allowability of Costs/Activities,' 2016, https://grants.nih.gov/grants/policy/nihgps/html5/section_7/ 7.9_allowability_of_costs_activities.htm.

36. D. Kingsley, 'Addressing the "Double Dipping" Charge,' Australian Open Access Strategy Group, February 27, 2014, https://aoasg.org.au/news-updates/blogsummary/addressing-the-double-dipping-charge/.

37. American Anthropological Association, 'Principles of Professional Responsibility,' 1986,

http://www.americananthro.org/ParticipateAndAdvocate/Content.aspx? ItemNumber=1656.

38. Boellstorf, 'Why the AAA Needs Gold Open Access.' 